\title{
Experimental testing of the critical loading for flexural-torsional buckling of steel two-chord columns laced in a single plane
}

\author{
P. Lorkowski \& B. Gosowski \\ Wroctaw University of Science and Technology, Wroctaw, Poland
}

\begin{abstract}
This paper presents the results of experimental research on the critical loading of two-chord steel columns laced in a single plane. Eight semi-technical scale physical models were constructed for the purposes of experimental testing, modelled on railway traction columns. Loading was focused at the level of the head and applied to an eccentric in the lacing plane. The goal of experimental testing was to determine the pathways to static equilibrium between the longitudinal force on the eccentric, and the bending angle of the cross-section at half the column height and its head displacement. The models were tested to structural failure. The forms of structural failure were observed in relation to flexural-torsional buckling of the column, as well as local buckling of the lacings. Critical forces of flexural-torsional buckling were determined using the Southwell method. The physical models were also analyzed numerically with the ABAQUS program using solid finite elements. Practice-oriented conclusions are presented.
\end{abstract}

\section{INTRODUCTION}

Steel columns with two-chord shafts and laced in a single plane are widely used as railway traction gate columns (Gosowski 2001). Such columns usually have branches consisting of structural channels, which are connected to form a single plane by means of flat or angled bars. A similar construction has been proposed for columns in industrial halls (Biegus 2009, Kucharczuk \& Labocha 2012, Guide of Design... 2003). In the case of halls with moving overhead cranes, the moving overhead part is usually constructed as an I-beam, whereas the bottom part is constructed from structural channels, I-beams or hollow profiles, laced at a $45^{\circ}$ angle.

Previous studies (Hasheela 2013, Lorkowski \& Gosowski 2018, Lorkowski \& Gosowski 2020) have shown the sensitivity of this type of structure to torsion, as well as spatial forms of stability loss. An additional contribution to the research on physical models referred to above and discussed in (Lorkowski \& Gosowski 2018) is the experimental testing presented in what follows, which is concerned with determining the critical loading for flexural-torsional buckling of steel columns laced in a single plane under eccentric compression conditions.

\section{DESCRIPTION OF ELEMENTS TESTED}

Two types of rods were tested for flexural-torsional buckling. They differed in terms of assembly method of the lacing. All the element types had branches (chords) made of rolled C 80 channels with axial spacing of $221 \mathrm{~mm}$ (see Figures 1, 2).

The lacing was made of square tubes RQ $40 \times 3 \mathrm{~mm}$ or FB $40 \times 5 \mathrm{~mm}$ flat bars and laid at an angle of $45^{\circ}$ in relation to the chords. The length of the chords was $4800 \mathrm{~mm}$, whereas with the nodal plates, the design height was $4937 \mathrm{~mm}$. The chords were made of S355 steel, whereas the plates and the lacing were made from S235 steel.

DOI: $10.1201 / 9781003132134-56$ 

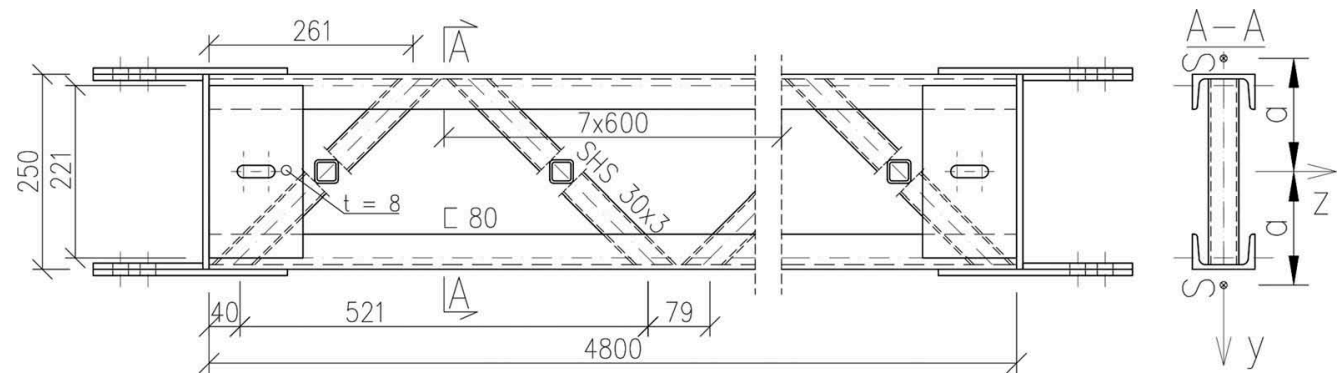

Figure 1. S-1 model with dimensions.

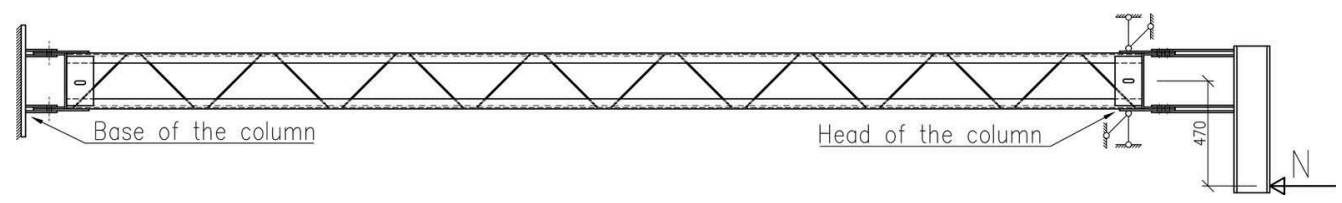

Figure 2. Schematic of column subjected to eccentric compression.

Figure 1 presents the S-1 physical model with a lacing structure made from square tubes, whereas in the S-2 physical model, the lacing was made with flat bars.

\section{PHYSICAL MODEL TESTING STATION}

The model of the column (cf. Figure 2) in the testing station was set up vertically. The base of the column provided a means for translational holding in all directions, as well as twisting around the longitudinal axis and rotation in the lacing plane. The rotation from the lacing plane was released. Displacement of the head of the column was blocked in both lateral directions, as well as the rotation around the longitudinal axis. The head allowed for displacement along the axis of the bar, as well as rotation in and out of the lacing plane. Deplaning at both ends of the column was blocked by nodal plates, diaphragm and lacings.

Loading was applied by means of a manual hydraulic cylinder with a load capacity of 200 $\mathrm{kN}$. The $N$ force was transferred to the model by means of a lever screwed to the model with 6 pre-stressing screws. The lever was used to apply the longitudinal force $\mathrm{N}$ on the eccentric. The eccentric force $\mathrm{N}$ was $e_{y}=470 \mathrm{~mm}$. The main parameter measured during the testing was the section torsion angle at half the column height. The measurement was carried out using four inductive displacement sensors with a range of $100 \mathrm{~mm}$ located in pairs in two perpendicular directions. Additionally, in order to control for stiffness of the support, the side displacements of the chords were measured in the head with two inductive sensors with a $10 \mathrm{~mm}$ range. They were negligibly small. The values of displacement and $N$ force were recorded by computer every 0.25 seconds. More detail concerning the testing station will be presented during the conference.

\section{EXPERIMENTAL TESTING OF THE PHYSICAL MODELS}

All models were inventoried prior to experimental testing. The dimensions of the rolled sections and dimensions (transverse and longitudinal) of the composite bar were checked, also for geometrical imperfections. As the deviations in the dimensions of rolled sections were found to be within acceptable tolerance limits, and the deviations of dimensions and 
imperfections were also within deviations specified in standards (PN-EN 1090-1, PN-EN 1090-2), the design dimensions of elements and nominal sections were adopted for further experimental testing (ArcelorMittal 2008, Bogucki \& Żyburtowicz 2006).

The models were subjected to eccentric compression in two or one loading cycles. The first of the models tested, i.e. S-1.1, S-2.1 and S-2.2 was subjected to a two-loading cycle, whereas the next one was subjected to a single loading cycle. The model S-2.1 was tested first, serving as a benchmark for subsequent experimental testing. This test had to be terminated and the results were rejected as unreliable due to an insufficient torsional hold on the head. Another model, S-1.1, was loaded with a preload of $20.02 \mathrm{kN}$ and then relieved. The permanent deformation was recorded in the form of a twisted shank amounting to $2 \times 10^{-4} \mathrm{rad}$. In the second cycle, the model was loaded with a force of $60.16 \mathrm{kN}$, which represented about $50 \%$ of the theoretical critical loading force. Further increase of the loading was interrupted due to the risk of the actuator slipping off the lever. Following modification of the actuator attachment, tests were carried out on the S-2.2 model. The loading regime was applied in two cycles, first the load was loaded to a value of about $20 \mathrm{kN}$, then relieved and reloaded until structural failure occurred. In the remaining models, loading was applied in a single cycle until structural failure occurred.

In models S-2.2 and S-2.3, the load capacity was exceeded with the loss of stability of the cross-braces. In the last model of the S-2 series, the cross-braces on the flat bar were reinforced by welding overlaps onto the cross-braces in order to determine when loading capacity was exceeded due to loss of overall stability of the column. The overlays were the same thickness as the flat bars of the lacing $(5 \mathrm{~mm})$ and $230 \mathrm{~mm}$ long. The caps were fixed with point-back welds. The testing of the pipe models was carried out yielding no surprises.

Measurements were obtained from the displacement sensors, which had been set in pairs 1-2 and 3-4, and placed in the middle of column height. Static equilibrium paths $\varphi-N$ were prepared for each post where $\varphi$ is the angle of twisting of the section. Critical forces of flexural-torsional buckling were determined using the Southwell method, with simple regression relationships (1) determined using the smallest squares method.

$$
\varphi=N_{c r, T F} \frac{\varphi}{N}+\varphi_{0}
$$

Figure 3 shows examples of the static equilibrium pathways of the S-1.2 column and the corresponding Southwell correlation graphs are shown in Figure 4.

Table 1 summarises the results of the model testing. Southwell relationships were used to calculate the value of the critical force for flexural-torsional buckling $N_{c r, T F}$, which was determined separately from the torsion angle on the basis of measurements from a pair of sensors 1-2 and $3-4$, which were used to calculate the arithmetic mean value $N_{c r, T F}$. The table also presents the load capacity limits $N_{g r}$ for the individual models.

Comparing the values obtained for the critical force of flexural-torsional buckling, it can be stated that displacement is greater in the case of elements with a piping lacing, than in the case of
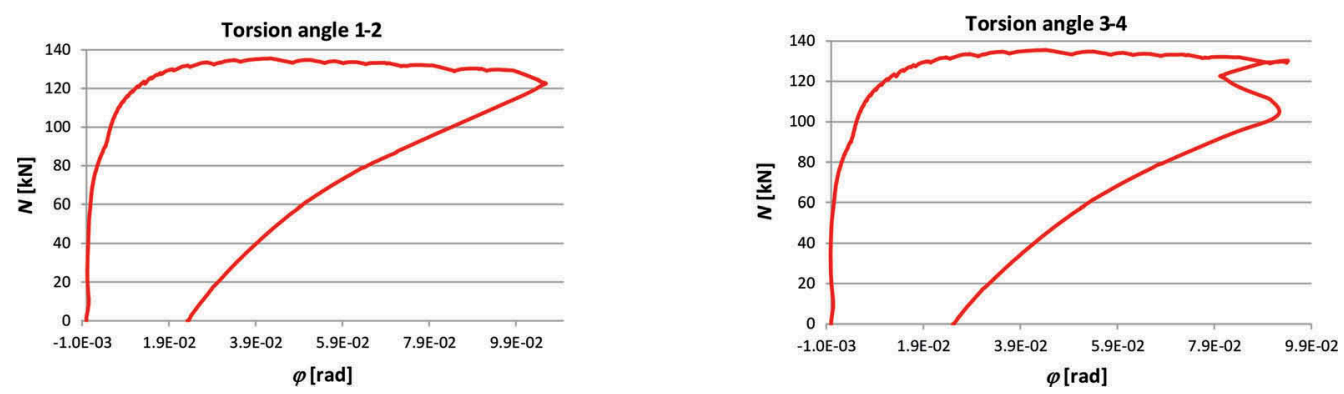

Figure 3. Static equilibrium paths $\varphi-N$ obtained during eccentric compression tests of model S-1.2. 

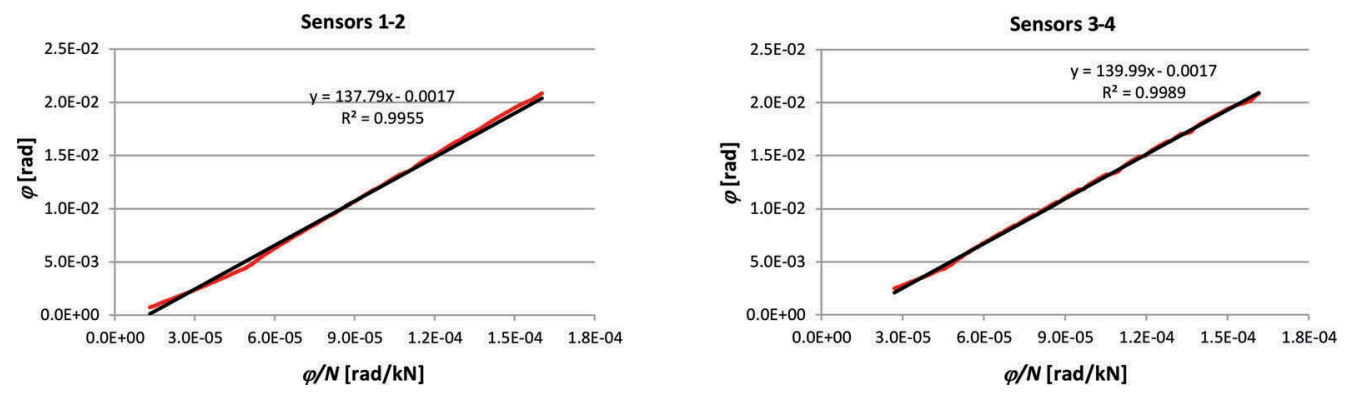

Figure 4. Graphs showing Southwell relationships determined for model S-1.2.

Table 1. Models S-1 and S-2 - presentation of results.

\begin{tabular}{|c|c|c|c|c|c|c|c|}
\hline \multirow[t]{4}{*}{ Model } & \multicolumn{4}{|c|}{ Sensor identification } & \multirow{3}{*}{$\begin{array}{l}\text { Average } \\
N_{c r, T F}\end{array}$} & \multirow[t]{3}{*}{$N_{g r}$} & \multirow{3}{*}{$\begin{array}{c}\text { Model } \\
\text { Failure }\end{array}$} \\
\hline & \multicolumn{2}{|l|}{$1-2$} & \multicolumn{2}{|l|}{$3-4$} & & & \\
\hline & $N_{c r, T F}$ & $R^{2}$ & $N_{c r, T F}$ & $R^{2}$ & & & \\
\hline & $\mathrm{kN}$ & - & $\mathrm{kN}$ & - & $\mathrm{kN}$ & $\mathrm{kN}$ & - \\
\hline S-1.1 & 150.17 & 0.9732 & 147.76 & 0.9558 & 148.97 & - & (1) \\
\hline S-1.2 & 137.79 & 0.9955 & 139.99 & 0.9989 & 138.89 & 135.59 & (2) \\
\hline S-1.3 & 134.03 & 0.9985 & 133.70 & 0.9996 & 133.87 & 129.67 & (2) \\
\hline S-1.4 & 150.84 & 0.9997 & 145.67 & 0.9997 & 148.26 & 141.19 & (2) \\
\hline S-2.1 & no results & & & & & & \\
\hline S-2.2 & 139.14 & 0.9722 & 134.79 & 0.9657 & 136.97 & 133.23 & (3) \\
\hline S-2.3 & 148.33 & 0.9962 & 145.01 & 0.9958 & 146.67 & 124.61 & (3) \\
\hline S-2.4 & 133.62 & 0.9987 & 128.68 & 0.9950 & 131.15 & 124.46 & (2) \\
\hline
\end{tabular}

(1) - did not result in structural failure, (2) - flexural-torsional buckling of column, (3) - flexural buckling of lacings.

columns with a flat bar lacing. It is important to note also that exceeding load-bearing capacity of the columns with flat bars led to a sudden structural failure with no prior indications evident.

\section{ANALYSIS OF RESULTS OF PHYSICAL MODEL TESTING}

The system of differential equations of flexural-torsional buckling of a bi-symmetric bar compressed by longitudinal force $N$ and bent in a plane of higher stiffness at a constant moment $M_{z}$ can be expressed in the following form (Gosowski 1999), (Weiss \& Giżejowski 1991):

$$
\begin{gathered}
E I_{y} \frac{\mathrm{d}^{4} w}{\mathrm{~d} x^{4}}+N \frac{\mathrm{d}^{2} w}{\mathrm{~d} x^{2}}+M_{z} \frac{\mathrm{d}^{2} \varphi}{\mathrm{d} x^{2}}=0 \\
E I_{\omega} \frac{\mathrm{d}^{4} \varphi}{\mathrm{d} x^{4}}+\left(N i_{o}{ }^{2}-G I_{T}\right) \frac{\mathrm{d}^{2} \varphi}{\mathrm{d} x^{2}}+M_{z} \frac{\mathrm{d}^{2} w}{\mathrm{~d} x^{2}}=0 .
\end{gathered}
$$

Assuming that the bending moment results from the longitudinal force applied on the eccentric $\left(M_{z}=-N \cdot e_{y}\right)$, the critical force of flexural-torsional buckling can be determined from the following formula (Gosowski 1999): 
Table 2. Values of coefficients $\mu_{y}, \mu_{T}$ and $c$ (Gosowski 1999).

\begin{tabular}{lllll}
\hline Support in the plane & & \multicolumn{2}{l}{ Length coefficient buckling } & Coefficient $c$ \\
\hline$x z$ & $y z$ & $\mu_{y}$ & $\mu_{T}$ & \\
\hline f-f & f-h & 0.5 & 0.7 & 0.78 \\
f-h & f-f & 0.7 & 0.5 & 0.78 \\
h-h & f-f & 1 & 0.5 & 0.77 \\
h-h & f-h & 1 & 0.7 & 0.83 \\
f-r & f-e & 1 & 0.2 & 0.83 \\
f-e & f-r & 2 & 1 & 0.79 \\
\hline
\end{tabular}

$\mathrm{h}$ - hinged, $\mathrm{f}$ - fixed, $\mathrm{e}$ - free end, $\mathrm{r}$ - restrained against rotation or warping but free translation or twist, respectively.

Table 3. Values $I_{\bar{T}}$ for models S-1 i S-2 and from earlier research.

\begin{tabular}{|c|c|c|c|c|c|c|}
\hline \multirow[t]{2}{*}{ Model } & \multicolumn{4}{|c|}{ Eccentric compression } & \multirow{2}{*}{$\begin{array}{l}\begin{array}{l}\text { Torsion } \\
\text { (L\&G 2018) }\end{array} \\
I_{\bar{T}, s^{\prime} r}\end{array}$} & \multirow{2}{*}{$\begin{array}{l}\text { Bending } \\
\text { (L\&G 2020) } \\
I_{\bar{T}, s^{\prime} r} \\
\end{array}$} \\
\hline & $N_{c r, T F}$ & $I_{\bar{T}}$ & $N_{c r, T F, s} r$ & $I_{\bar{T}, s^{\prime} r}$ & & \\
\hline & $\mathrm{kN}$ & $\mathrm{cm}^{3}$ & $\mathrm{kN}$ & $\mathrm{cm}^{3}$ & $\mathrm{~cm}^{3}$ & $\mathrm{~cm}^{3}$ \\
\hline S-1.1 & 148.97 & 32.811 & 142.50 & 26.25 & 19.04 & 20.80 \\
\hline S-1.2 & 138.89 & 22.299 & & & & \\
\hline S-1.3 & 133.87 & 17.902 & & & & \\
\hline S-1.4 & 148.26 & 31.985 & & & & \\
\hline S-2.1 & - & - & 138.26 & 22.16 & 16.60 & 17.26 \\
\hline S-2.2 & 136.97 & 20.555 & & & & \\
\hline S-2.3 & 146.67 & 30.191 & & & & \\
\hline S-2.4 & 131.15 & 15.724 & & & & \\
\hline
\end{tabular}

$$
N_{c r, T F}=\frac{i_{o}{ }^{2}\left(N_{y}+N_{T}\right) \pm \sqrt{i_{o}{ }^{4}\left(N_{y}+N_{T}\right)^{2}+4 \cdot e_{y}{ }^{2} \cdot i_{o}{ }^{2} \cdot N_{y} \cdot N_{T}}}{2\left(i_{o}{ }^{2}-c \cdot e_{y}{ }^{2}\right)}
$$

where: $N_{y}, N_{T}$ - critical buckling force: flexural and torsional respectively, $i_{o}$ - polar radius of inertia with respect to the centre of gravity, $e_{y}$ - eccentricity of the force; $c$ - coefficient depending on support conditions, which is equal to 1 at $\mu_{y}=\mu_{T}$, and at $\mu_{y} \neq \mu_{T}$ takes on the values presented in Table 2 .

On the basis of the critical force of flexural-torsional buckling determined in the experimental tests, transforming the formula (4) accordingly, makes it possible to determine the equivalent pure torsional moment of inertia $I_{\bar{T}}$. Material constants $E=205 \mathrm{GPa}, v=0.3$ and relevant coefficients with the following values were adopted: $c=0.77, \mu_{y}=1, \mu_{T}=0.5$. The notional sectorial moment of inertia was determined from the relationships presented by Lorkowski \& Gosowski (2018)

$$
I_{\bar{\omega}}=2\left(I_{\omega p}+a^{2} \cdot I_{y p}\right)
$$

where: $I_{y p}, I_{\omega p}-$ the moment of inertia about $y$-axis and the sectorial moment of inertia of a single chord respectively, $a$ - the distance from the shearing source of the chords (cf. Figure 1).

The values obtained for $I_{\bar{T}}$. are presented in Table 3, in which the two final columns provide for comparative purposes, the results from testing of the similar models for torsion and bending. 
Table 4. Summary of results for eccentric compression, torsional and bending models.

\begin{tabular}{|c|c|c|c|c|}
\hline \multirow[t]{2}{*}{ Model } & \multicolumn{2}{|c|}{ Eccentric compression } & \multirow{2}{*}{$\frac{\text { Torsion (L\&G 2018) }}{I_{\bar{T}},}$} & \multirow{2}{*}{$\begin{array}{l}\text { Bending (L\&G 2020) } \\
I_{\bar{T}},\end{array}$} \\
\hline & $N_{c r, T F}$ & $I_{\bar{T}}$ & & \\
\hline & $\mathrm{kN}$ & $\mathrm{cm}^{3}$ & $\mathrm{~cm}^{3}$ & $\mathrm{~cm}^{3}$ \\
\hline S-1 & 138.14 & 21.61 & 16.69 & 15.67 \\
\hline S-2 & 135.55 & 19.32 & 14.09 & 13.31 \\
\hline
\end{tabular}

\section{TESTING WITH NUMERICAL MODELS}

Numerical model testing was carried out using the ABAQUS program for calculations (ABAQUS 2012). The program is based on the Finite Element Method (FEA).

Calculations using the ABAQUS program were performed with resources made available by the Wrocław Supercomputer Network (http://wcss.pl), under the calculation grant No. 306.

The models were generated in the CAE module, whereas calculations were made using the STANDARD module. The models were divided into solid, 8-node finite elements, with reduced integration (C3D8R), and in places where the geometry of the model did not allow for it - 6-node solid elements (C3D6). Solid elements, in contrast to coated elements, take into account the deformation of the cross-section throughout its thickness, so they are better suited for testing the types of structures with which we are concerned here (Gosowski \& Niżniowski 2008). The size of finite elements was selected so as to ensure the maximum length did not exceed $8 \mathrm{~mm}$. The number of finite elements, depending on the model type was in the range of $65 \div 98$ thousand.

Material constants were adopted as for the physical models. As the focus of concern was not the analysis in the extra-elastic range, a linear-elastic material model was assumed.

The calculation procedure assumed three steps. The initiating step, in which the support conditions were defined, the first step - overall static analysis and the second step - stability analysis. The stability analysis was carried out using the buckle procedure, which belongs to the group of linear instabilities

In the case of the S-1 model, the programme generated 15 eigenvalues, which fell within the force range defined (between 130 and $160 \mathrm{kN}$ ), with only one of them taking on a form of overall stability loss, which was interpreted as the critical force for flexural-torsional buckling.

In the case of the S-2 model, 24 eigenvalues were found to lie in the force range between 110 and $150 \mathrm{kN}$. The value that had the lowest positive value and a generalisable form was interpreted as the critical force for flexural-torsional buckling.

Table 4 shows the calculation results for the eccentric compressive models S-1 and S-2. The first column presents the first eigenvalue relating to the loss of overall stability, which is also the critical force of flexural-torsional buckling. On the basis of this value, $I_{\bar{T}}$. was calculated. The formula (4) was used for this purpose, and the solution was obtained using an iterative method. In the last two columns the values $I_{\bar{T}}$, are presented for purposes of comparison. These value were obtained from torsional and bending numerical analysis.

The comparison of the two models from the point of view of the critical force for flexuraltorsional buckling leads to the conclusion that there is little benefit from using pipes over flat bars for the lacing. However, a comparison of results of loading capacity limit results indicates a clear advantage of using piping for the lacing.

\section{SUMMARY AND CONCLUSIONS}

The tests carried out on the elements of concern for eccentric compression confirm their sensitivity to spatial loss of stability, when compared to quasi-closed lacing elements. In addition, 
both FEM testing and physical model testing confirm that bars with pipe lacing exhibit more favourable behaviour in relation to localized stability. In the case of elements subjected to compression, this is important as the stability loss pathway of cross-braces with flat bars takes place suddenly without prior indication.

When the load-bearing capacity is exceeded, more than half of the compressed bars with flat bars buckled. In contrast to elements subjected to bending, a different failure mechanism appears. In elements subjected to bending, the cause of stability loss is related to localised loading of cross-braces in response to changes in the support structure. In the case of eccentric compression, the loading on the cross-braces comes mainly from the transverse force of the column body. Stability loss of one of the cross-braces results in it being excluded from loading transfer and, in consequence, demands that forces are transferred through the remaining cross-braces. It is this that results in a rapid, cascading loss of stability of the remaining crossbraces. This phenomenon is especially dangerous in relation to important load-bearing structures. Incorrect diagnosis of this phenomenon may result in structural failure.

\section{REFERENCES}

ABAQUS 6.12. 2012 Online Documentation. Dassault Systèmes.

Biegus, A. 2009. Stalowe budynki halowe. Warszawa: Arkady.

Gosowski, B. 1999. Spatial buckling of thin-walled steel-construction beam-columns with discrete bracings. Journal of Constructional Steel Research 52: 293-317.

Gosowski, B. 2001. Problems of durability of steel in railway overhead structures. Ochrona przed Korozja. 2: 40-44 (in Polish).

Gosowski, B. \& Niżniowski, P. 2008. Verification of FEM program solutions of stability and torsion problems for I shape steel members. Archives of Civil Engineering 54(1): 129-145.

Guide for the Design and Construction of mill buildings AISE. 2003. Technical Report No. 13, Pittsburgh, Pennsylvania

Hasheela P.F. 2013. Behaviour of single laced columns versus double laced columns. Johannesburg. MSc Thesis.

Kucharczuk, W. \& Labocha, L. 2012. Hale o konstrukcji stalowej. Poradnik projektanta. Rzeszów: Polskie Wydawnictwo Techniczne.

Lorkowski, P. \& Gosowski B. 2018. Experimental and numerical research of the torsion problem of built-up steel columns laced in a single plane. Engineering Structures, 160, 566-580.

Lorkowski P. \& Gosowski B. 2020 Investigations for lateral buckling of two chords steel members laced in a single plane. Inżynieria i Budownictwo 1: 50-55 (in Polish).

Weiss S. \& Giżejowski M. 1991. Stateczność konstrukcji metalowych. Układy prętowe, Arkady, Warszawa. 